\title{
Erratum to: Complete genome sequence of Colocasia bobone disease-associated virus, a putative cytorhabdovirus infecting taro
}

\author{
Colleen M. Higgins ${ }^{1,2} \cdot$ Nicolas Bejerman ${ }^{3} \cdot \operatorname{Ming} \mathrm{Li}^{1,2} \cdot$ Anthony P. James ${ }^{4} \cdot$ \\ Ralf G. Dietzgen $^{3} \cdot$ Michael N. Pearson ${ }^{5} \cdot$ Peter A. Revill ${ }^{4,6} \cdot$ Robert M. Harding $^{4}$
}

Published online: 4 August 2016

(C) Springer-Verlag Wien 2016

\section{Erratum to: Arch Virol (2016) 161:745-748 \\ DOI 10.1007/s00705-015-2713-7}

Unfortunately, Fig. 1 was incorrectly published in the original publication of the article. The correct version of Fig. 1 is given here:

The online version of the original article can be found under doi:10.1007/s00705-015-2713-7.

Colleen M. Higgins

colleen.higgins@aut.ac.nz

1 Institute of Applied Ecology, School of Applied Sciences,

Auckland University of Technology,

Private Bag 92006, Auckland 1142, New Zealand

2 AUT Roche Diagnostic Laboratory, Auckland University of Technology, Private Bag 92006, Auckland 1142, New

Zealand

3 Queensland Alliance for Agriculture and Food Innovation, The University of Queensland, St Lucia, QLD 4072, Australia

4 Centre for Tropical Crops and Biocommodities, Queensland University of Technology, GPO Box 2434, Brisbane, QLD 4001, Australia

5 School of Biological Sciences, The University of Auckland, Private Bag 92019, Auckland 1142, New Zealand

6 Present Address: Victorian Infectious Diseases Reference Laboratory, Doherty Institute of Infection and Immunity, 792 Elizabeth St, Melbourne, VIC 3000, Australia 


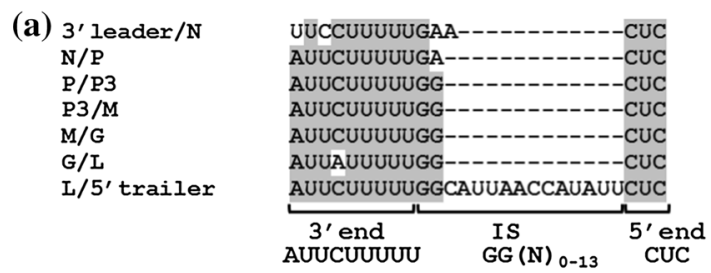

(c)

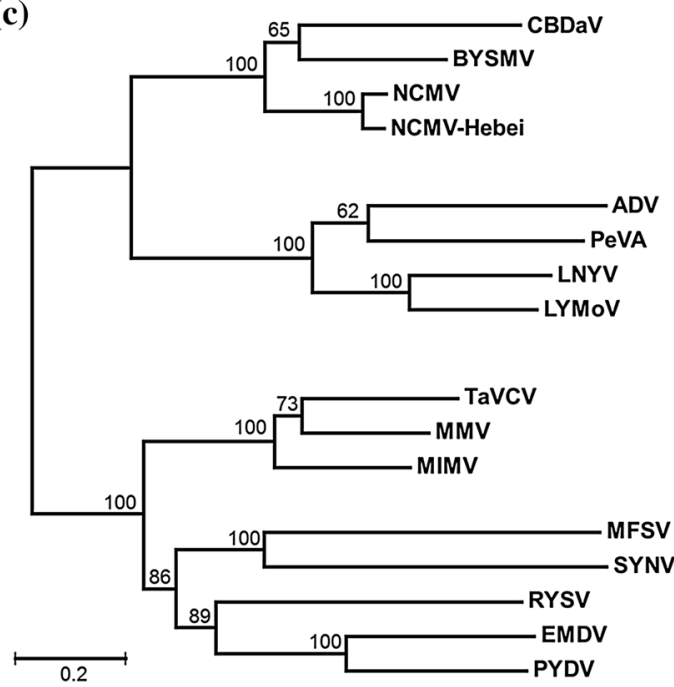

(b)

\begin{tabular}{|c|c|c|c|}
\hline CBDaV & AUUCUUUUU & $\mathrm{GGN}_{\mathrm{n}}$ & CUC \\
\hline BYSMV & AUUAUUUUU & GA & CUC \\
\hline NCMV & AUUCUUUUU & GACU & CUA \\
\hline LYMOV & AUUCUUUU & $\mathrm{GN}_{\mathrm{n}}$ & CUN \\
\hline LNYV & AUUCUUUUU & $\mathrm{GN}_{\mathrm{n}}$ & CUA \\
\hline TaVCV & AUUCUUUUU & GG & GUU \\
\hline MMV & AUUCUUUUU & GG & GUU \\
\hline ¿SV & AUUAUUUUU & GG & UUG \\
\hline SYNV & AUUCUUUUU & GG & UUG \\
\hline MFSV & UUUAUUU & GUAG & UUG \\
\hline & & IS & \\
\hline
\end{tabular}

$\left.\begin{array}{l}\left.\begin{array}{l}\text { Planthopper? (CBDV) } \\ \text { Planthopper } \\ \text { Planthopper } \\ \text { Planthopper } \\ \text { Aphid } \\ \text { Unknown } \\ \text { Aphid } \\ \text { Unknown } \\ \text { Unknown } \\ \text { Planthopper } \\ \text { Planthopper } \\ \text { Leafhopper } \\ \text { Aphid } \\ \text { Leafhopper } \\ \text { Leafhopper } \\ \text { Leafhopper }\end{array}\right] \text { Nucleorhabdovirus } \\ \hline\end{array}\right]$

Fig. 1 a) Similarity between sequences corresponding to predicted $3^{\prime}$ ends of CBDaV mRNAs, intergenic sequences (IS) and $5^{\prime}$ end of the next mRNA. The sequences are provided in the $3^{\prime}-5^{\prime}$ sense of the viral mRNAs. Dashes indicate gaps introduced to optimise the alignment, while conserved nucleotides are highlighted in grey. b) Consensus sequences of the gene junction regions of $\mathrm{CBDaV}$ compared with other plant rhabdoviruses [3, 9]. c) Maximum-likelihood analysis using the GTR $+\mathrm{G}+\mathrm{I}$ model, of plant rhabdovirus $\mathrm{L}$ polymerase open reading frame nucleotide sequences. The tree is rooted at the midpoint, the insect vectors for each virus are shown, and nucleorhabdovirus and cytorhabdovirus clades are indicated by brackets. Bootstrap values greater than 50 are shown for the major nodes, and the scale indicates the number of substitutions per site. Virus abbreviations are as noted in the text 